\title{
Nasal Immunization with a Recombinant HIV gp120 and Nanoemulsion Adjuvant Produces Th1 Polarized Responses and Neutralizing Antibodies to Primary HIV Type 1 Isolates
}

\author{
ANNA U. BIELINSKA, ${ }^{1}$ KATARZYNA W. JANCZAK, ${ }^{1}$ JEFFREY J. LANDERS, ${ }^{1}$ \\ DAVID M. MARKOVITZ, ${ }^{2}$ DAVID C. MONTEFIORI, ${ }^{3}$ AND JAMES R. BAKER, JR. ${ }^{1}$
}

\begin{abstract}
Epidemiological and experimental data suggest that both robust neutralizing antibodies and potent cellular responses play important roles in controlling primary HIV-1 infection. In this study we have investigated the induction of systemic and mucosal immune responses to HIV gp120 monomer immunogen administered intranasally in a novel, oil-in-water nanoemulsion (NE) adjuvant. Mice and guinea pigs intranasally immunized by the application of recombinant HIV gp120 antigen mixed in NE demonstrated robust serum anti-gp120 IgG, as well as bronchial, vaginal, and serum anti-gp120 IgA in mice. The serum of these animals demonstrated antibodies that cross-reacted with heterologous serotypes of gp120 and had significant neutralizing activity against two clade-B laboratory strains of HIV (HIV BaL $_{\text {and }}$ HIV SF162 $_{2}$ ) and five primary HIV-1 isolates. The analysis of gp120-specific CTL proliferation, INF- $\gamma$ induction, and prevalence of anti-gp120 IgG2 subclass antibodies indicated that nasal vaccination in NE also induced systemic, Th1-polarized cellular immune responses. This study suggests that NE should be evaluated as a mucosal adjuvant for multivalent HIV vaccines.
\end{abstract}

\section{INTRODUCTION}

$\mathbf{T}$ HE UNIQUE IMMUNOBIOLOGY OF HIV, the diversity of virus isolates, variables in the immunogenicity of viral antigens, and the lack of clear correlates of protection with specific aspects of anti-HIV immunity have all raised fundamental questions about the potential for protective HIV vaccination. ${ }^{1-3}$ Despite this, multiple approaches for the development of a vaccine to prevent HIV infection or control virus-associated disease have been attempted. The HIV envelope glycoprotein (Env) is a major target for neutralizing antibodies. ${ }^{4}$ Because of its central role in mediating virus binding to cellular CD4 and facilitating coreceptor interaction, the gp120 component of Env, in both monomeric and native oligomeric forms, has been used as a principal HIV vaccine immunogen. ${ }^{5,6}$ Unfortunately, initial attempts to employ gp120 as a traditional vaccine immunogen failed. ${ }^{7-9}$ Because epidemiological and immunological evidence suggests that an effective HIV vaccine will need to elicit both virus-specific neutralizing antibodies and cytotoxic $\mathrm{T}$ cell responses against HIV-1, ${ }^{10-16}$ recent HIV vaccines explored various combinations of viral and/or DNA vectors and recombinant Env proteins. ${ }^{3,17-21}$ While some of these approaches may work, many are complex and it is clear new approaches are still needed. ${ }^{22-24}$

Primary HIV-1 infection typically occurs via mucosal surfaces turning attention to vaccines that could induce anti-HIV mucosal immunity. Intranasal immunizations have been reported to induce both mucosal and systemic immune responses. ${ }^{19,25,26}$ Several experimental and commercial human nasal vaccines for mucosally transmitted viral and bacterial pathogens have been pursued in recent years. ${ }^{27-30}$ In contrast, initial candidate HIV vaccines have predominantly used traditional human adjuvants not associated with mucosal immunity and have been administered by subcutaneous injection. ${ }^{3,14} \mathrm{~A}$ few recent HIV vaccine approaches have attempted mucosal immunization through multiple strategies, including inactivated HIV-1, ${ }^{31,32}$ live-attenuated viral vectors, ${ }^{33,34}$ bacterial vectors, ${ }^{35,36}$ virus-like particles (VLPs), ${ }^{37}$ naked DNA, ${ }^{38,39}$ toxins,

\footnotetext{
${ }^{1}$ Michigan Nanotechnology Institute for Medicine and Biological Sciences (MNIMBS), University of Michigan, Ann Arbor, Michigan 48109.

${ }^{2}$ Internal Medicine, Infectious Diseases, University of Michigan, Ann Arbor, Michigan 48109.

${ }^{3}$ Department of Surgery, Laboratory for AIDS Vaccine Research and Development, Duke University Medical Center, Durham, North Carolina 27706.
} 
and cytokines. ${ }^{40-42}$ However, both safety concerns regarding attenuated pathogens and side effects from mucosal bacterial toxin-containing adjuvants have limited the use of these approaches for human mucosal vaccines. ${ }^{43-45}$ Therefore, the lack of safe and effective mucosal adjuvants capable of eliciting both neutralizing antibodies and cytotoxic T lymphocyte (CTL)-mediated responses limits development of mucosal vaccines, especially for HIV. ${ }^{46-48}$

The current studies evaluate an oil-in-water nanoemulsion (NE) as a mucosal adjuvant for a recombinant gp120 HIV vaccine. Previous studies have demonstrated that NEs have broad antimicrobial activity ${ }^{49,50}$ and are safe and effective noninflammatory mucosal adjuvants for influenza and recombinant anthrax protective antigen vaccines. ${ }^{51,52}$ In the present work, the nanoemulsion was simply mixed with recombinant gp120 and applied to the nares of mice and guinea pigs. We then assessed the induction of both mucosal and systemic anti-gp120 antibodies and the cross-reactivity of these antibodies with different gp120 serotypes, and also evaluated the animal's sera for HIV neutralization activity. In addition, we characterized the systemic gp120-specific cellular response induced by mucosal immunization with NE adjuvant. Our results suggest that this type of NE deserves further evaluation as adjuvant for an HIV vaccine.

\section{MATERIALS AND METHODS}

\section{Animals}

Pathogen-free, female BALB/c mice (5-6 weeks old) and Hartley guinea pigs (females, $250 \mathrm{~g}$ ) were purchased from Charles River Laboratories (Wilmington, MA). The mice and guinea pigs were cared for in accordance with the American Association for Accreditation of Laboratory Animal Care standards. All procedures involving animals were approved by the University Committee on Use and Care of Animals (UCUCA) at the University of Michigan.

\section{Reagents}

Recombinant HIV gp120 $\mathrm{BaL}$ and gp120 ${ }_{\mathrm{SF} 162}$ serotype proteins produced in yeast were obtained from Quantum Biological, Inc., through The NIAID Vaccine Research Resource. The $5 \mathrm{mg} / \mathrm{ml}$ aliquots of the protein solutions in a sterile saline were stored at $-80^{\circ} \mathrm{C}$ until used. The synthetic V3 loop peptide $(\mathrm{BaL})$ was obtained as a gift from Dr. Steven King (University of Michigan). The 20-mer oligonucleotide (ODN) 5'-TCC ATG ACG TTC CGT ACG TT -3',53 containing nonmethylated CpG repeats, was synthesized by Integrated DNA Technologies (IDT, Coralville, IA). The Salmonella minnesota monophosphoryl lipid A (MPL A, \#L-6638), phytohemagglutinin protein (PHA-P), bovine serum albumin (BSA), dithiothreitol (DTT), and other chemicals used in buffers were purchased from Sigma-Aldrich Corporation (St. Louis, MO). The saline solution, phosphate-buffered saline (PBS), cell culture media, and fetal bovine serum (FBS) were purchased from GIBCO (Grand Island, NY) and HyClone (Logan, UT), respectively. The alkaline phosphatase (AP)-conjugated antibodies, goat antimouse $\mathrm{IgG}$, and goat antimouse $\operatorname{IgA}$ ( $\alpha$ chain specific) were purchased from Sigma. The secondary antibodies, AP conjugates rabbit antimouse IgG1, IgG2a, IgG2b, and IgG3 and rabbit anti-guinea pig IgG, were bought from Rockland Immunochemicals, Inc.

\section{Preparation of the gp120/adjuvant formulations}

The oil-in-water NE used in these studies was supplied by NanoBio Corporation (Ann Arbor, MI). NE was produced by the emulsification of cetylpyridinium chloride (CPC, 1\%), a nonionic surfactant $(5 \%)$, and ethanol $(8 \%)$ in water with hotpressed soybean oil (64\%), using a high-speed emulsifier. ${ }^{49}$ Except for the CPC, this nanoemulsion is formulated with surfactant and food substances considered "Generally Recognized as Safe" (GRAS) by the Food and Drug Administration (FDA). NE mean droplet size (approximately $350 \mathrm{~nm}$ in diameter) was determined by dynamic light scattering (DLS) using the NICOMP 380 ZLS (PSS NICOMP Particle Sizing Systems, Santa Barbara, CA).

All gp120/NE formulations were prepared by mixing gp120 protein solution with NE, using pyrogen-free saline as a diluent. Murine immunization studies were performed with a $20 \mu \mathrm{g}$ dose of gp120 mixed with $0.1 \%, 0.5 \%$, and $1 \%$ NE concentrations. For immunization with additional immunostimulants, either $5 \mu \mathrm{g}$ of MPL A or $10 \mu \mathrm{g} \mathrm{CpG} \mathrm{ODN} \mathrm{was} \mathrm{added} \mathrm{to} 20 \mu \mathrm{g}$ gp120 in $1 \% \mathrm{NE}$ or to $20 \mu \mathrm{g}$ gp120 in saline. A guinea pig immunization study was performed using a $50 \mu \mathrm{g}$ dose of gp120 mixed with $1 \% \mathrm{NE}$ and normal saline as diluent.

\section{Immunization procedures}

$\mathrm{BALB} / \mathrm{c}$ mice (five animals per group) were immunized with two, and on one occasion with three, intranasal administrations of gp120/NE formulation at 3 weeks apart. The immunizations were performed by slowly applying gp120/NE mixes (10 $\mu \mathrm{l}$ per nare) to the nares of isoflurane-anesthetized mice. During administration, animals were held in the inverted position until the droplets were completely inhaled. Control mice were immunized with gp120 in saline, with NE alone or saline. Intramuscular immunization was performed with two doses, 3 weeks apart, of $20 \mu \mathrm{g}$ gp120 injected in $50 \mu \mathrm{l}$ of either saline or $1 \%$ NE. Hartley guinea pigs (three animals per group) were anesthetized with the ketamine injection $(40 \mathrm{mg} / \mathrm{kg})$ and immunized intranasally with two intranasal administrations of gp120/NE $\operatorname{mix}(50 \mu \mathrm{l}$ per nare) at 3 weeks apart.

\section{Collection of blood, bronchial alveolar lavage, vaginal washes, and splenocytes}

Blood samples were obtained before and 3 weeks after final immunizations either from the saphenous vein, at various time points during the course of the experiment, or by cardiac puncture from euthanized premorbid mice. Serum was obtained from coagulated blood (30-60 $\mathrm{min}$ at room temperature) by centrifugation at $1500 \times g$ for $5 \mathrm{~min}$. Collected serum samples were heat inactivated at $56^{\circ} \mathrm{C}$ for $1 \mathrm{~h}$ and stored at $-20^{\circ} \mathrm{C}$ until analyzed.

Mouse bronchial alveolar lavage (BAL) fluid was obtained from animals euthanized by inhalation of isoflurane. The lung was infused twice with $0.5 \mathrm{ml}$ of PBS with $10 \mu \mathrm{M}$ DTT and $0.5 \mathrm{mg} / \mathrm{ml}$ aprotinin and approximately $1 \mathrm{ml}$ of aspirate was recovered. BAL samples were stored at $-20^{\circ} \mathrm{C}$ until analyzed. Vaginal wash samples were collected from anesthetized mice 
by infusion of vaginal cavities with $100 \mu \mathrm{l}$ of PBS with $10 \mu \mathrm{M}$ DTT and $0.5 \mathrm{mg} / \mathrm{ml}$ aprotinin. The samples were centrifugated at $10,000 \times \mathrm{g}$ for $5 \mathrm{~min}$ at $4^{\circ} \mathrm{C}$, and the supernatants were stored at $-20^{\circ} \mathrm{C}$ until analyzed.

Murine splenocytes were mechanically isolated to obtain single cell suspension in PBS. The red blood cells (RBC) were removed by lysis with ACK buffer $\left(150 \mathrm{mM} \mathrm{NH}_{4} \mathrm{Cl}, 10 \mathrm{mM}\right.$ $\mathrm{KHCO}_{3}, 0.1 \mathrm{mM} \mathrm{Na}{ }_{2}$ EDTA), and the remaining cells were washed twice in PBS. For the antigen-specific proliferation or cytokine expression assays, splenocytes $\left(2-4 \times 10^{6}\right.$ cells $\left./ \mathrm{ml}\right)$ were resuspended in RPMI 1640 medium, supplemented with $2 \%$ FBS, L-glutamine, and penicillin/streptomycin $(100 \mathrm{U} / \mathrm{ml}$ and $100 \mu \mathrm{g} / \mathrm{ml})$.

\section{Determination of anti-gp120 IgG and IgA antibodies}

Mouse anti-gp120-specific IgG and IgA levels were determined by enzyme-linked immunosorbent assay (ELISA). Microtiter plates (MaxiSorp; Nalge Nunc International, Rochester, NY) were coated with $5 \mu \mathrm{g} / \mathrm{ml}(100 \mu \mathrm{l})$ of either gp $120_{\mathrm{BaL}}$ or gp $120_{\mathrm{SF} 162}$ serotype envelope protein in the coating buffer (50 mM sodium carbonate, $50 \mathrm{mM}$ sodium bicarbonate, $\mathrm{pH} 9.6$ ) and incubated overnight at $4{ }^{\circ} \mathrm{C}$. After the protein solution was removed, plates were blocked for $30 \mathrm{~min}$ at $37^{\circ} \mathrm{C}$ with $\mathrm{PBS}-1 \%$ dry milk solution. The blocking solution was aspirated and plates were used immediately or stored sealed at $4{ }^{\circ} \mathrm{C}$ until needed. Serum and BAL samples were serially diluted in $0.1 \%$ BSA in PBS, and $100 \mu \mathrm{l} /$ well aliquots were incubated in gp120coated plates for $1 \mathrm{~h}$ at $37^{\circ} \mathrm{C}$. The plates were washed three times with PBS- $0.05 \%$ Tween 20 , followed by $1 \mathrm{~h}$ incubation with either antimouse $\mathrm{IgG}$ or antimouse $\operatorname{IgA}$ AP-conjugated antibodies, then washed three times and incubated with AP substrate SigmaFast (Sigma, St. Louis, MO) according to the manufacturer's protocol. Spectrophotometric readouts were performed using the Spectra Max 340 ELISA reader (Molecular Devices, Sunnyvale, CA) at $405 \mathrm{~nm}$ and reference wavelength of $690 \mathrm{~nm}$. Endpoint antibody titers were defined as the last reciprocal serial serum dilution at which the absorption at $405 \mathrm{~nm}$ was greater than two times absorbance above negative control. Guinea pig anti-gp120 IgG was determined by the same method, except that rabbit anti-guinea pig IgG AP conjugate (Rockland) was used for detection. Antibody concentrations are presented as the mean \pm standard deviation (SD) of endpoint titers.

\section{HIV-1 single-round neutralization assay}

The panel of eight strains of clade B HIV-1 used in this study consists of the laboratory strains $\mathrm{BaL}, \mathrm{SF} 162$, and $\mathrm{MN}$, and primary HIV-1 isolates SS1196.11, BG1168.1, QH0692.42, 3988.25 , and $5768.04 .{ }^{54}$ Virus neutralization was measured as a function of the reductions in luciferase reporter gene expression after a single round of virus infection in TZM-bl cells as described previously. ${ }^{55}$ The TZM-bl cells are engineered to express CD4 and CCR5 and contain integrated reporter genes for firefly luciferase and Escherichia coli $\beta$-galactosidase under control of an HIV-1 LTR. Primary HIV-1 isolates TCID $_{50}$, 100-200) were incubated in triplicate with serial dilutions of sera for $1 \mathrm{~h}$ at $37^{\circ} \mathrm{C}$. Subsequently virus/serum mixtures were added to the 96-well flat-bottom culture plate containing adherent TZM-bl cells. Control consisted of cells plus virus (virus control) and cells only (background control). Bioluminescence was measured after $48 \mathrm{~h}$ using Bright Glo substrate solution per the supplier's protocol (Promega, Madison, WI). Neutralization titers $\left(\mathrm{NT}_{50}\right)$ are the dilutions at which relative light units (RLUs) were reduced by $50 \%$ compared to those of virus control wells after subtraction of background RLUs.

\section{Proliferation assay}

The proliferation of mouse splenocytes was measured by 5 bromo-2-deoxyuridine (BrdU) incorporation using a commercial kit (Cell Proliferation ELISA, Roche Molecular Biochemicals, Mannheim, Germany). To assess antigen-specific proliferation, cells $\left(2 \times 10^{6} \mathrm{cell} / \mathrm{ml}\right)$ were incubated with and without $\mathrm{gp} 120_{\mathrm{BaL}}(5 \mu \mathrm{g} / \mathrm{ml})$, and as a positive control PHA-P ( $2 \mu \mathrm{g} / \mathrm{ml}$, for $48 \mathrm{~h}$, then pulsed with BrdU for $24 \mathrm{~h}$ ). Cell proliferation was measured according to the manufacturer's instructions using a Spectra Max 340 ELISA Reader (Molecular Devices, Sunnyvale, CA) at $370 \mathrm{~nm}$ and reference wavelength of $492 \mathrm{~nm}$.

\section{Analysis of cytokine expression in vitro}

Mouse splenocytes were seeded at $4 \times 10^{6}$ cells/ml (RPMI $1640,2 \%$ FBS $)$ and incubated with either gp120 $0_{\mathrm{BaL}}, \mathrm{gp} 120_{\mathrm{SF} 162}$ $(5 \mu \mathrm{g} / \mathrm{ml})$, or with V3 loop peptide $(20 \mathrm{nM})$ for $72 \mathrm{~h}$ at $37^{\circ} \mathrm{C}$. Cell culture supernatants were harvested and analyzed for the presence of cytokines. The cytokine assays were performed using Quantikine ELISA kits (R\&D Systems, Inc., Minneapolis, $\mathrm{MN}$ ) according to the manufacturer's instructions.

\section{Statistical analysis}

Statistical analysis of the results was preformed using ANOVA, and Student's $t$-test for the determination of the $p$ value.

\section{RESULTS}

Nasal immunization with recombinant HIV gp120 protein mixed with nanoemulsion induces anti-gp120 IgG antibodies in serum

$\mathrm{BALB} / \mathrm{c}$ mice were intranasally immunized with either gp120 $\mathrm{BaL}$ or gp120 ${ }_{\mathrm{SF} 162}$ serotypes to assess whether NE has adjuvant activity in mucosal immunization with recombinant gp120 protein. Immunizations were carried out using $20 \mu \mathrm{g}$ of gp $120_{\mathrm{BaL}}$ in either saline or mixed with $0.1 \%, 0.5 \%$, and $1 \%$ $\mathrm{NE}$ concentrations. Blood samples collected at 6 weeks after prime immunization (in animals boosted only at 3 weeks) and at 12 weeks after prime immunization (in animals boosted at 3 and 6 weeks) were analyzed for gp120-specific antibodies by ELISA. All mice immunized with either of the gp120 $\mathrm{BaL} / \mathrm{NE}$ preparations were seropositive after only two immunizations (Fig. 1). The anti-gp120 $\mathrm{BaL}$ IgG response showed a concentration-dependent effect of $\mathrm{NE}$, with the lowest titers in gp $120_{\mathrm{BaL}} / 0.1 \% \mathrm{NE}$ and highest in gp $120_{\mathrm{BaL}} / 1 \% \mathrm{NE}$ immunization groups (mean titers of $1.3 \times 10^{4}$ and $2.6 \times 10^{5}$, respectively, Fig. 1A). In contrast, mice immunized with gp120 BaL in saline did not have detectable anti-gp120 $\mathrm{BaL}$ antibodies even after three immunizations. Serum anti-gp120 IgG 


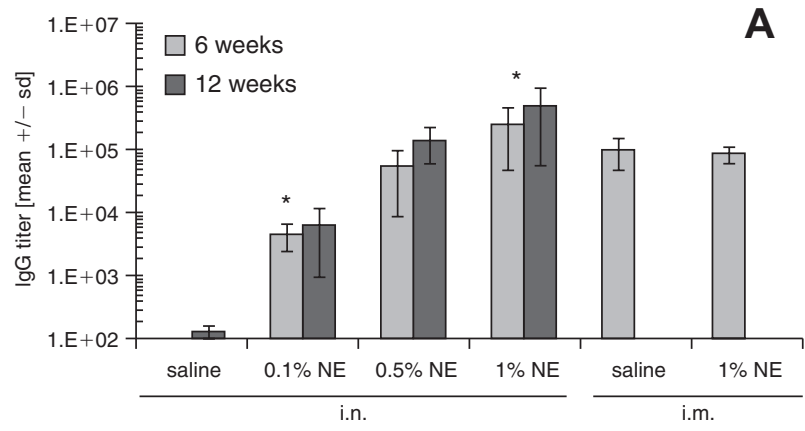

Immunization with gp120 $\mathrm{BaL}$

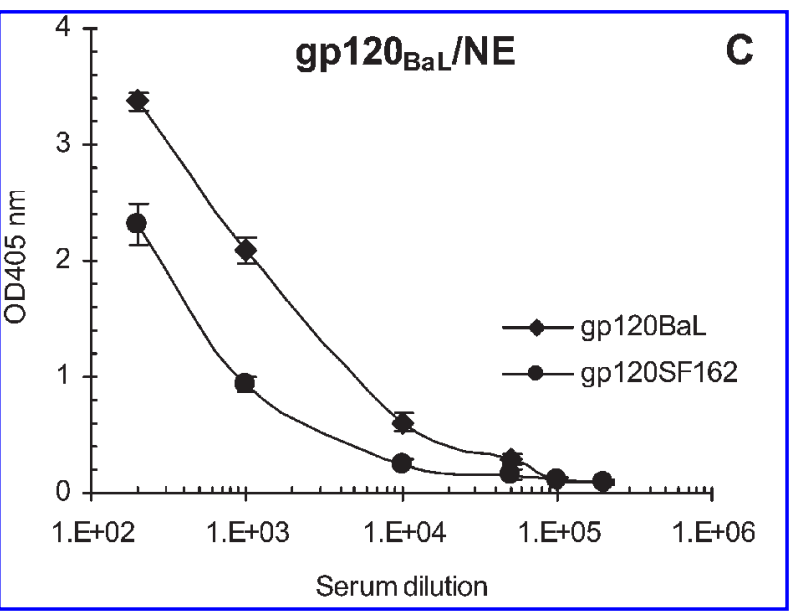

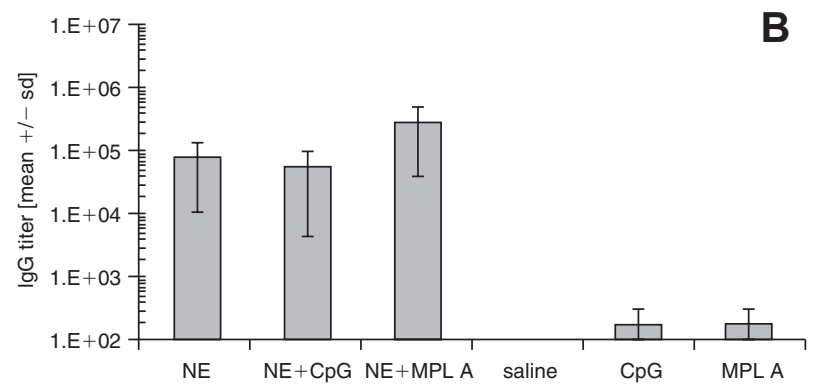

Immunization with gp120 ${ }_{\mathrm{SF} 162}$
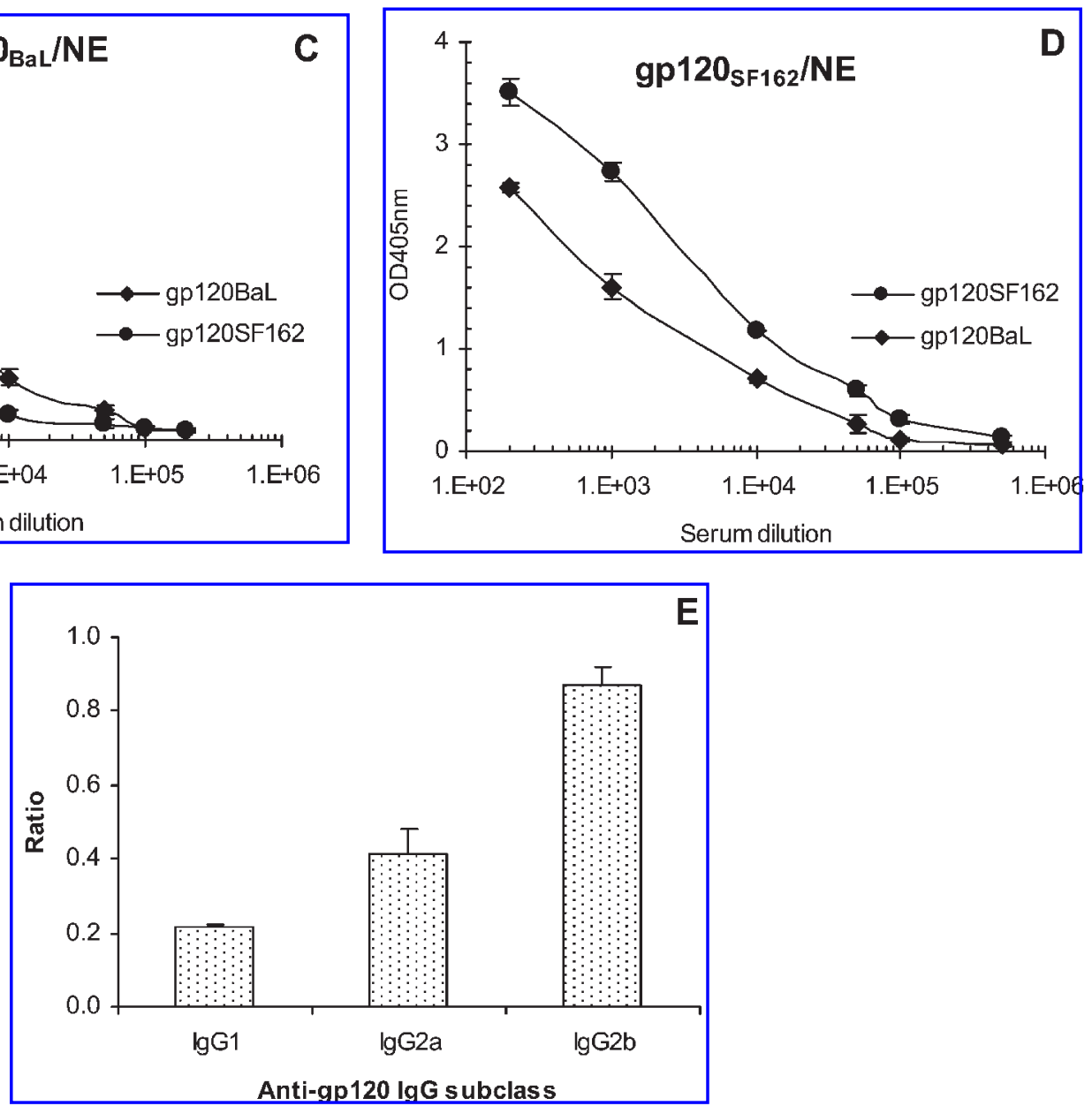

FIG. 1. Antibody response in mice intranasally vaccinated with two serotypes of recombinant gp 120 and the nanoemulsion adjuvant. (A) Induction of serum anti-gp120 $\mathrm{BaL}$ IgG in mice immunized with gp120 $\mathrm{BaL}$ in $0.1 \%, 0.5 \%$, and $1 \% \mathrm{NE}$. Anti-gp120 $\mathrm{BaL}$ blood samples collected at 6 weeks after prime immunization (in animals boosted only at 3 weeks) and at 12 weeks after prime immunization (in animals boosted at 3 and 6 weeks) were analyzed for gp120-specific antibodies by ELISA. Intranasal (i.n.) and intramuscular (i.m.) routes of immunization are indicated in the Figure. (B) Induction of anti-gp120 $\mathrm{SF} 162$ IgG in mice i.n. immunized with two doses of gp120 $\mathrm{SF}_{62}$ in $1 \% \mathrm{NE}$ alone or with addition of $\mathrm{CpG}$ or MPL A. Anti-gp120 IgG antibodies were measured at 6 weeks after prime immunization (in animals boosted at 3 weeks). Anti-gp120 antibody levels are presented as a mean of endpoint titers $( \pm$ SD) in serum of individual animals. Cross-reactivity of the anti-gp120 antibodies. Serum IgG from mice immunized with either gp120 $\mathrm{BaL}_{2}(\mathbf{C})$ or gp120 $\mathrm{SF162}_{2}$ (D) reacts with both gp120 serotypes. Data are presented as titration curves of pooled serum from all immunized animals binding to either gp120 $0_{\text {SF162 }}$ or $120_{\mathrm{BaL}}$. (E) Anti-gp120 IgG subclass pattern in mice immunized i.n. with gp120/NE. The results are presented as a titer ratio of the specific subclass IgG to the overall IgG titer. 
titers after intranasal immunization with either $0.5 \%$ or $1 \% \mathrm{NE}$ were comparable with the antibody response obtained after two intramuscular injections with gp $120_{\mathrm{BaL}}$ in saline or mixed with $1 \% \mathrm{NE}$, and the addition of a third intranasal immunization did not significantly increase antibody titers (Fig. 1A). These results indicate that two intranasal gp120 $\mathrm{BaL} / \mathrm{NE}$ immunizations produce a systemic immune response in mice.

Additional studies examining the NE immunizations were carried out with a second gp120 serotype, gp120 $0_{\text {SF162 }}$. Similarly to immunization with the gp120 $\mathrm{BaL}$, all mice immunized with gp $120_{\mathrm{SF} 162} / \mathrm{NE}$ responded with high anti-gp120 ${ }_{\mathrm{SF} 162} \mathrm{IgG}$ titers. NE-produced immune responses were not enhanced significantly by the addition of unmethylated $\mathrm{CpG}$ ODN and MPL A (Fig. 1B). To investigate the effect of combining the NE with other immunostimulants, mice were immunized with the gp120 ${ }_{\mathrm{SF} 162} / \mathrm{NE}$ with the addition of either $\mathrm{CpG}$ $\left(\mathrm{gp}^{120_{\mathrm{SF} 162}} / \mathrm{NE}+\mathrm{CpG}\right)$ or MPL A $\left(\mathrm{gp} 120_{\mathrm{SF} 162} / \mathrm{NE}+\mathrm{MPL}\right.$ A). Combining NE with MPL A (but not with $\mathrm{CpG}$ ) resulted in a modest increase in mean antibody titer of 2- to 3-fold over immunization with gp120 ${ }_{\mathrm{SF} 162} / \mathrm{NE}$ alone; however, this difference was not statistically significant $(p>0.05)$. In contrast, nasal immunization with gp $120_{\text {SF162 }}$ antigen mixed with either CpG or MPL A alone produced minimal immune responses (Fig. 1B).

Intranasal immunization with either serotype of gp120 protein in NE produced cross-reacting IgG antibodies to the other serotype (Fig. 1C and D). Serum IgG antibodies raised against either gp120 $\mathrm{BaL}$ or gp120 $\mathrm{SF}_{\mathrm{S} 162}$ reacted with the other serotype with activity comparable to the immunizing envelope protein and similar endpoint titers. This suggested that NE adjuvant produced a repertoire of IgG capable of recognizing both variable and conserved epitopes of the gp120 immunogen, which could be of importance for protective immunity against different serotypes of HIV-1. ${ }^{56}$ The subclass analysis of the antigp120 IgG antibodies indicated a prevalence of $\operatorname{IgG} 2 \mathrm{~b}$ and IgG2a over IgG1 antibodies, thus suggesting Th1 polarization of the immune response in mice immunized with gp120/NE (Fig. 1E). The absence of antibody response to intranasal. immunization with gp120 antigen alone did not allow for the determination of IgG subclass without NE adjuvation.

\section{Induction of secretory mucosal anti-gp120 IgA and $\operatorname{Ig} G$}

BAL fluids, vaginal washes, and sera were analyzed for evidence of mucosal response. Mice nasally immunized with gp120 ${ }_{\mathrm{SF} 162} / \mathrm{NE}$ had significant levels of gp120 ${ }_{\mathrm{SF} 162}$-specific secretory IgA and IgG antibodies in BAL fluid (Fig. 2A and B). Similar to serum $\mathrm{IgG}$, both mucosal $\mathrm{IgA}$ and $\mathrm{IgG}$ responses demonstrate cross-reactivity with the gp120 $\mathrm{BaL}$ immunogen. Anti-gp120 $\mathrm{BaL}$ IgA was also detected in the serum and importantly in secretions from distant (vaginal) mucosa after intranasal NE immunization (Fig. 2C). In contrast, immunization with either type of gp120 in saline failed to produce any type of mucosal IgA and IgG response.

\section{Cell-mediated immune responses}

Cellular immune responses were assessed in vitro by antigen-specific T cell proliferation and the pattern of cytokine production. Antigen-specific proliferative responses were detected only in splenic lymphocytes from animals immunized with the gp $120_{\mathrm{BaL} / \mathrm{NE}}$ and were absent in either mice immunized with either gp $120_{\mathrm{BaL}} /$ saline or with control animals treated with saline or NE alone (Fig. 3A). Intranasal immunization with gp120 BaL/NE also produced systemic, cross-reacting, cell-mediated immunity as demonstrated by significant interferon (IFN)- $\gamma$ production after in vitro stimulation with either gp120 $\mathrm{BaL}$ or gp120 ${ }_{\mathrm{SF} 162}$ in cells harvested from animals immunized with gp120 $\mathrm{BaL}$ (Fig. 3B). A substantial induction of the IFN- $\gamma$ was also obtained in these splenic cells with an oligopeptide fragment of the V3 loop, thus indicating the presence of cells recognizing the dominant epitope associated with virus binding and neutralization. ${ }^{9,57}$ In contrast, there was no antigen-specific induction of interleukin (IL)-4 expression (not shown), suggesting a Th1 polarization of the cellular immune response. In addition, no significant cytokine response was stimulated by gp120 in splenocytes from either control, nonimmune mice, or from mice immunized with gp $120_{\mathrm{BaL}}$ in saline.

\section{Immunization with gp120/NE induces antibodies that neutralize HIV-1}

To investigate the ability of gp120-specific antibodies induced by NE nasal immunization to neutralize HIV, guinea pigs were immunized with two doses of gp $120_{\mathrm{SF} 162}$ in $1 \%$ NE. Immunization again produced significant levels of serum antigp120 IgG antibodies in all animals (Fig. 4A) and as observed with the murine immunizations the serum anti-gp 120 IgG crossreacted with the gp $120_{\mathrm{BaL}}$ immunogen. The immune sera from guinea pigs were then tested for neutralizing activity against HIV-1. The breadth of the neutralizing response was evaluated using a panel of eight viruses, including three laboratory strains and five primary HIV-1 isolates. Figure 4B documents that the highest $\mathrm{NT}_{50}$ occurred in a single animal with the immunizing serotype bearing M-tropic strain of $\mathrm{HIV}_{\mathrm{SF} 162}$ with an $\mathrm{NT}_{50}=$ 225. Neutralizing activity was also present, albeit at lower levels $\left(\mathrm{NT}_{50}>50\right)$, in the two other animals immunized with this antigen despite lower anti-gp120 IgG levels. Of interest, significant neutralization was also observed with six of the seven other HIV isolates (including all five primary isolates), with all three guinea pigs generating an $\mathrm{NT}_{50}$ of at least 50 and exceeding 100 with two of the primary isolates (Fig. 4B). No neutralization was observed with the laboratory strain of T-tropic HIV $_{\text {MN virus. }}$

\section{DISCUSSION}

Mucosal vaccines have the unique ability to induce both mucosal and systemic immunity. This is potentially important in the prevention of respiratory or sexually transmitted infections. However, antigens delivered via mucosal routes are usually not immunogenic and require adjuvants to enhance immunogenicity. ${ }^{26,58-62}$ In this study we have demonstrated that intranasal immunization with recombinant gp120 administered in a nanoemulsion adjuvant induces potent systemic and mucosal immune responses. In contrast to other mucosal HIV vaccines in development, which reportedly require three or four immunizations, ${ }^{41,59,60,62,63}$ the NE adjuvanted material produced high titers of anti-gp120 antibodies after only two administrations. 

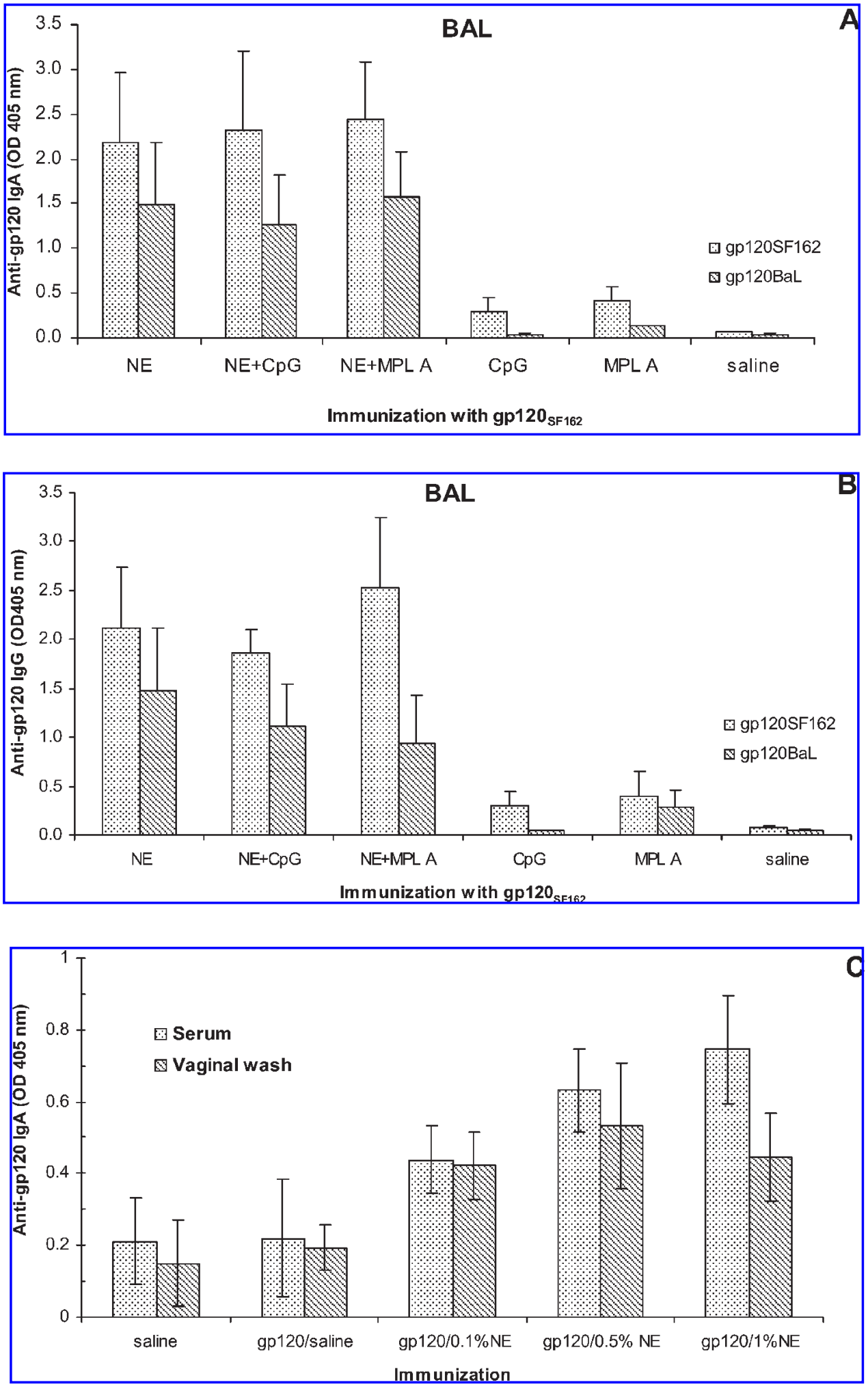

FIG. 2. Nasal immunization with gp120/NE induces mucosal IgA and IgG antibodies. Secretory anti-gp120 IgA (A) and IgG (B) in bronchial lavage (BAL). The IgA and IgG antibodies recognize both autologous SF162 and heterologous BaL serotypes as indicated. Assays were performed with undiluted and 1:10 diluted BAL fluids for IgA and IgG, respectively. (C) Anti-gp120 IgA in serum and in the vaginal washes of mice vaccinated with gp $120_{\mathrm{BaL}}$ and NE adjuvant. Assays were performed with undiluted vaginal washes and with 1:50 diluted serum. Anti-gp120 IgA and $\operatorname{IgG}$ concentrations are presented as mean absorbance $(\mathrm{OD} 405 \mathrm{~nm} \pm \mathrm{SD})$ obtained in ELISA. A statistically significant difference was observed between gp120/saline and all gp120/NE groups $(p<0.05)$, but no significant differences were observed in various NE concentrations $(p>0.05)$. 


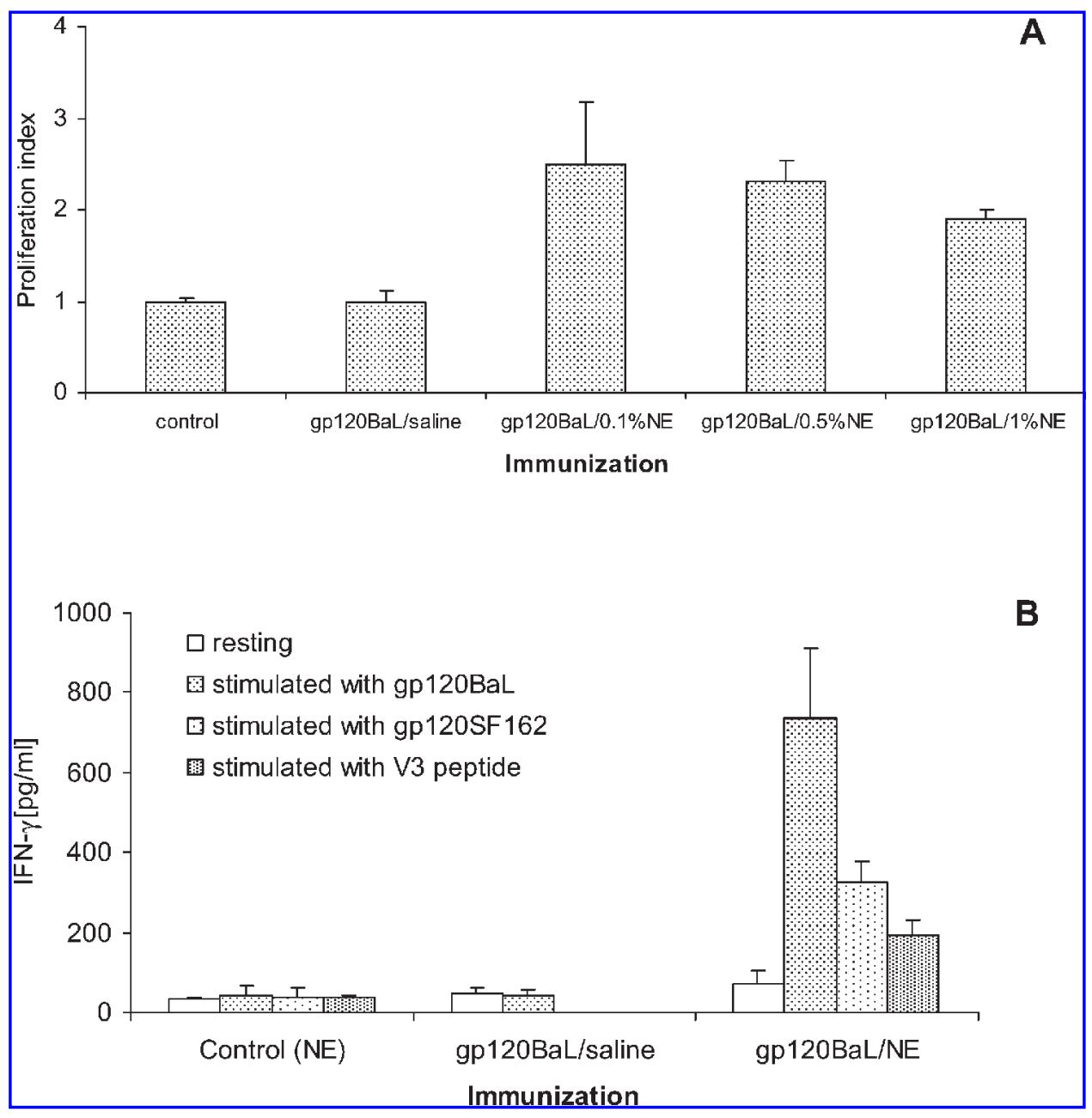

FIG. 3. (A) Antigen-specific splenocyte proliferation. Splenocytes from animals immunized with gp $120_{\mathrm{BaL}}$ were stimulated in vitro with $2 \mu \mathrm{g} / \mathrm{ml}$ of this anitgen. Cell proliferation was normalized to controls and presented as mean \pm SD of individual proliferation indexes. The differences between the gp $120_{\mathrm{BaL}} /$ saline and the gp $120_{\mathrm{BaL}} / \mathrm{NE}$ groups were all statistically significant $(p<$ 0.05). (B) Antigen-specific activation of cytokine production in splenocytes in vitro. Splenocytes from mice immunized with gp120 12 aL were activated with $5 \mu \mathrm{g} / \mathrm{ml}$ of either gp120 $\mathrm{BaL}$ or gp120 $0_{\mathrm{SF} 162}$, and with $20 \mathrm{nM}$ of the V3 loop peptide. IFN- $\gamma$ in cell supernatants was determined by ELISA and concentrations are presented as the mean of individual samples \pm SD.

In addition, serum IgG gp120 titers were comparable to those reported for intramuscular immunization ${ }^{59,60}$ and those obtained when we intramuscularly immunized mice (Fig. 1). The response to NE-based nasal immunization also compared favorably with responses achieved through parenteral, bimodal vaccine regiments of multiple DNA injections (three or four) followed by subsequent boosts with recombinant antigen or adenoviral vector. ${ }^{21,64,65}$

Nasal immunization with gp120/NE also induced significant antigen-specific $\mathrm{IgA}$ and $\mathrm{IgG}$ antibodies in BAL fluid and vaginal secretions. The IgA in these compartments may result from local IgA production, which is supported by finding these antibodies in both bronchial alveolar and vaginal mucosal secretions. These results support the concept that nasal mucosa immunization can produce specific antibody responses in distant mucosal sites. ${ }^{40,66-68}$ The presence of anti-HIV antibodies in the genital tract could be useful in the prevention of HIV-1 infection. ${ }^{2,69-71}$
A major goal in the design of the HIV vaccine is to generate high titers of antibodies that can neutralize many different isolates of HIV. ${ }^{20}$ Multiple studies and clinical trials with gp120-based vaccines document that despite high titers of antigp120 antibodies there is often limited neutralizing activity against naturally occurring HIV-1 isolates. ${ }^{6,56}$ Mucosal immunization with gp120/NE induced highly cross-reactive IgG and $\operatorname{IgA}$ antibodies against two diverse serotypes of gp120, BaL and SF162, in both mice and guinea pigs. The relevance of this result was further illustrated in the HIV-1 neutralization analysis. When tested for neutralizing activity against a panel of clade B HIV-1 strains, sera from guinea pigs nasally immunized with gp20 ${ }_{\text {SF162 }} / \mathrm{NE}$ demonstrated broad, neutralizing activity against seven of eight strains and against all five primary HIV-1 isolates. This included neutralization of the phylogenetically diverse clones BG1168.1, SS1196.11, QH0692.42, 3988.25, and 5768.4. These isolates were chosen because of their inclusion in the recently proposed list of clade B HIV-1 clones for the 


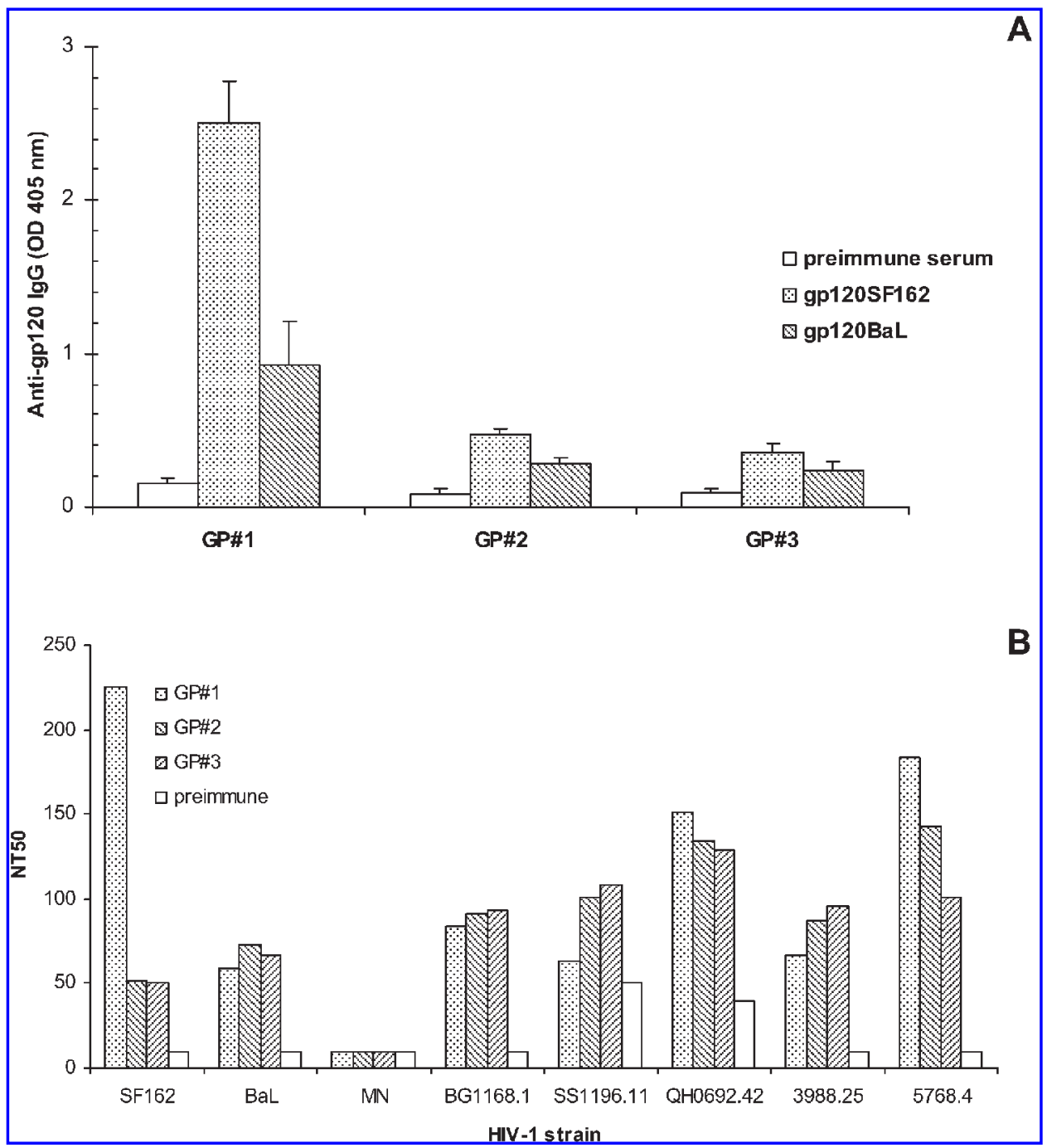

FIG. 4. (A) Nasal immunization of guinea pigs. Hartly guinea pigs (GP) were nasally vaccinated with $50 \mu \mathrm{g}$ gp $120_{\mathrm{SF} 162}$ in $1 \%$ NE then boosted i.n. with the same dose 3 weeks later. The serum IgG antibody response toward gp120 $0_{\text {SF } 162}$ and gp120 $\mathrm{BaL}$ serotypes was then measured at 6 weeks after initial immunization. Anti-gp120 IgGs are presented as OD $405 \mathrm{~nm} \pm$ SD obtained in an ELISA using 1:200 dilutions of serum and either gp120 ${ }_{\mathrm{SF} 162}$ or gp120 $\mathrm{BaL}$ as the coating antigen. (B) Neutralizing antibody produced by i.n. immunization with gp $120_{\mathrm{SF} 162} / \mathrm{NE}$. The neutralization of the laboratory strains and the primary isolates of HIV was performed in the TZM-bl cell system. $\mathrm{NT}_{50}$ values represent the serum dilution at which relative luminescence units (RLU) were reduced 50\% compared to virus control. Individual preimmune sera from the same animals were used to determine background antiviral activity.

standardized assessment of vaccine-induced neutralizing antibodies. ${ }^{54,72,73}$ Sequence and glycosylation site analysis indicated a wide spectrum of genetic diversity, as expected for virus strains obtained from independent infections. The reason for this extensive cross-neutralization activity may involve stabilization of the gp120 protein conformation, especially as a trimer, by NE (data not shown). These data suggest a mucosal vaccine consisting of multiple serotypes of recombinant HIV1 proteins and NE adjuvant could potentially produce even broader-spectrum HIV-1 neutralizing activity.

Interestingly, no significant neutralizing activity was found against another clade B laboratory strain- $-\mathrm{HIV}_{\mathrm{MN}}$. It is not clear if this insensitivity may be related to the diversity of V3 loop epitope, which is linked to T-tropism of this viral isolate. ${ }^{74}$
In earlier studies and in vaccine trials, gp120 $\mathrm{MN}$ and gp160 $\mathrm{MN}$ failed to produce neutralizing antibodies to the majority of HIV1 isolates, ${ }^{75,76}$ so there may be something uniquely nonimmunogenic about this strain.

While NE nasal immunization induced potent systemic and mucosal antibodies, it also induced significant cellular immune responses, as documented by antigen-specific proliferation and IFN- $\gamma$ production in splenic lymphocytes. The induction of hallmark Th1 cytokine IFN- $\gamma$ indicates activation of $\mathrm{CD}^{+}$and $\mathrm{CD} 8{ }^{+}$CTLs with both autologous gp $120_{\mathrm{BaL}}$ and heterologous gp120 ${ }_{\text {SF162 }}$ and with 35 aa V3 loop peptide. ${ }^{77,78}$ The pattern of cytokine induction with significant INF- $\gamma$ and absence of IL-4 suggests that NE alone can produce the Th1 polarization cellular response. ${ }^{79}$ The cytokine data are supported by the anal- 
ysis of the anti-gp120 IgG isotype contribution to overall antibody response. A significant prevalence of $\operatorname{IgG} 2$ ( $b$ and a) over IgG1 subclass antibodies clearly indicates a Th1 bias produced by NE vaccination. ${ }^{80}$ In contrast, combining NE adjuvant with adjuvants such as $\mathrm{CpG}$ or MPL $\mathrm{A}^{58,81}$ did not have a significant effect on the response to immunization. The lack of $\mathrm{CpG}$ effect could be due to a nonoptimized oligonucleotide sequence and to the relatively low dose of $\mathrm{CpG}$ used in the study. ${ }^{21,82-84}$ The addition of MPL A resulted in only a minimal, nonsignificant increase in serum antibody titers, which is in accordance with the findings of VanCott et al. ${ }^{83}$ where intranasal immunization was performed with gp160/liposome/MPL A. It is a possibility that mixing MPL A with lipids can lower activity as reported with liposome formulations. ${ }^{84}$ In any case, it appears that this mucosal adjuvant activity is unique and requires the presence of NE.

In summary, data presented in these studies illustrate that nasal gp120/NE immunization produces a systemic and mucosal antibody response with significant, cross-reactive neutralizing immunity and a Th1 polarized CTL response. The mucosal adjuvant capability could be helpful in the design of novel HIV vaccines.

\section{ACKNOWLEDGMENTS}

The authors wish to express their thanks to Gloria Benko and Donna Gauss for help in preparation of this manuscript. Support for these studies came from the Michigan Nanotechnology Institute for Medicine and the Biological Sciences (M-NIMBS) and the Ruth Dow Doan Endowment. Dr. D.M. Markovitz was supported by the Burroughs Welcome Fund.

\section{REFERENCES}

1. Burton DR: A vaccine for HIV type 1: The antibody perspective. Proc Natl Acad Sci USA 1997;94:10018-10023.

2. Burton DR, Desrosiers RC, Doms RW, et al.: HIV vaccine design and the neutralizing antibody problem. Nat Immunol 2004;5:233-236.

3. Letvin NL: Progress and obstacles in the development of an AIDS vaccine. Nat Rev Immunol 2006;6:930-939.

4. Srivastava IK, Stamatatos L, Legg H, et al.: Purification and characterization of oligomeric envelope glycoprotein from a primary R5 subtype B human immunodeficiency virus. J Virol 2002;76: 2835-2847.

5. Barnett SW, Lu S, Srivastava I, et al.: The ability of an oligomeric human immunodeficiency virus type 1 (HIV-1) envelope antigen to elicit neutralizing antibodies against primary HIV-1 isolates is improved following partial deletion of the second hypervariable region. J Virol 2001;75:5526-5540.

6. Spearman P: Current progress in the development of HIV vaccines. Curr Pharm Des 2006;12:1147-1167.

7. Cohen J: Public health: AIDS vaccine still alive as booster after second failure in Thailand. Science 2003;302:1309a-1310.

8. McMichael AJ: HIV vaccines. Annu Rev Immunol 2006;24: 227-255.

9. Takahashi, Nakagawa Y, Pendleton CD, et al.: Induction of broadly cross-reactive cytotoxic T cells recognizing an HIV-1 envelope determinant. Science 1992;255:333-336.

10. Baba TW, Liska V, Hofmann-Lehmann R, et al: : Human neutralizing monoclonal antibodies of the IgG1 subtype protect against mucosal simian-human immunodeficiency virus infection. $\underline{\text { Nat }}$ Med 2000;6:200-206.

11. Betts MR, Nason MC, West SM, et al.: HIV nonprogressors preferentially maintain highly functional HIV-specific CD8 + T cells. Blood 2006;107:4781-4789.

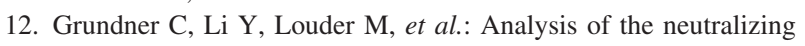
antibody response elicited in rabbits by repeated inoculation with trimeric HIV-1 envelope glycoproteins. Virology 2005;331:33-46.

13. Koup RA, Safrit JT, Cao Y, et al.: Temporal association of cellular immune responses with the initial control of viremia in primary human immunodeficiency virus type 1 syndrome. J Virol 1994; 68:4650-4655.

14. Nabel GJ: Challenges and opportunities for development of an AIDS vaccine. Nature 2001;410:1002-1007.

15. Ogg GS, Jin X, Bonhoeffer S, et al.: Quantitation of HIV-1-specific cytotoxic T lymphocytes and plasma load of viral RNA. Science 1998;279:2103-2106.

16. Rosenberg ES, Altfeld M, Poon SH, et al.: Immune control of HIV1 after early treatment of acute infection. Nature 2000;407: 523-526.

17. Catanzaro AT, Koup RA, Roederer M, et al.: Phase 1 safety and immunogenicity evaluation of a multiclade HIV-1 candidate vaccine delivered by a replication-defective recombinant adenovirus vector. J Infect Dis 2006;194:1638-1649.

18. Graham BS, Koup RA, Roederer M, et al.: Phase 1 safety and immunogenicity evaluation of a multiclade HIV-1 DNA candidate vaccine. J Infect Dis 2006;194:1650-1660.

19. Neutra MR and Kozlowski PA: Mucosal vaccines: The promise and the challenge. Nat Rev Immunol 2006;6:148-158.

20. Pantaleo G and Koup RA: Correlates of immune protection in HIV1 infection: What we know, what we don't know, what we should know. Nat Med 2004;10:806-810.

21. Shu Y, Winfrey S, Yang Z-y, et al.: Efficient protein boosting after plasmid DNA or recombinant adenovirus immunization with HIV-1 vaccine constructs. Vaccine 2007;25:1398-1408.

22. Goepfert PA, Horton H, McElrath MJ, et al.: High-dose recombinant canarypox vaccine expressing HIV-1 protein, in seronegative human subjects. J Infect Dis 2005;192:1249-1259.

23. Lu X, Wu S, Blackwell CE, Humphreys RE, von Hofe E, and Xu M: Suppression of major histocompatibility complex class II-associated invariant chain enhances the potency of an HIV gp120 DNA vaccine. Immunology 2007;120:207-216.

24. Mazzoli S, Trabaironi D, Caputo SL, et al.: HIV-specific mucosal and cellular immunity in HIV-seronegative partners of HIVseropositive individuals. Nat Med 1997;3:1250-1257.

25. Vajdy M, Singh M, Kazzaz J, et al.: Mucosal and systemic antiHIV responses in rhesus macaques following combinations of intranasal and parenteral immunizations. AIDS Res Hum Retroviruses 2004;20:1269-1281.

26. Vajdy M, Srivastava I, Polo J, Donnelly J, O'Hagan D, and Singh M: Mucosal adjuvants and delivery systems for protein-, DNA- and RNA-based vaccines. Immunol Cell Biol 2004;82:617-627.

27. Balmelli C, Demotz S, Acha-Orbea H, De Grandi P, and NardelliHaefliger D: Trachea, lung, and tracheobronchial lymph nodes are the major sites where antigen-presenting cells are detected after nasal vaccination of mice with human papillomavirus type 16 viruslike particles. J Virol 2002;76:12596-12602.

28. Gallichan WS, Woolstencroft RN, Guarasci T, McCluskie MJ, Davis HL, and Rosenthal KL: Intranasal immunization with CpG oligodeoxynucleotides as an adjuvant dramatically increases IgA and protection against herpes simplex virus- 2 in the genital tract. J Immunol 2001;166:3451-3457.

29. Takada A, Matsushita S, Ninomiya A, Kawaoka Y, and Kida H: Intranasal immunization with formalin-inactivated virus vaccine induces a broad spectrum of heterosubtypic immunity against influenza A virus infection in mice. Vaccine 2003;21:3212-3218. 
30. Yasuda $\mathrm{Y}$, Isaka M, Taniguchi T, et al.: Frequent nasal administrations of recombinant cholera toxin B subunit (rCTB)-containing tetanus and diphtheria toxoid vaccines induced antigen-specific serum and mucosal immune responses in the presence of anti-rCTB antibodies. Vaccine 2003;21:2954-2963.

31. Akagi T, Kawamura M, Ueno M, Hiraishi K, Adachi M, Serizawa T, Akashi M, and Baba M: Mucosal immunization with inactivated HIV-1-capturing nanospheres induces a significant HIV-1-specific vaginal antibody response in mice. J Med Virol 2003;69:163-172.

32. Dumais N, Patrick A, Moss RB, Davis HL, and Rosenthal KL: Mucosal immunization with inactivated human immunodeficiency virus plus $\mathrm{CpG}$ oligodeoxynucleotides induces genital immune responses and protection against intravaginal challenge. J Infect Dis 2002;186:1098-1105.

33. Amara RR, Villinger F, Altman JD, et al: Control of a mucosal challenge and prevention of AIDS by a multiprotein DNA/MVA vaccine. Vaccine 2002;20:1949-1955.

34. Gherardi MM and Esteban M: Recombinant poxviruses as mucosal vaccine vectors. J Gen Virol 2005;86:2925-2936.

35. Golding B, Eller N, Levy L, et al.: Mucosal immunity in mice immunized with HIV-1 peptide conjugated to Brucella abortus. Vaccine 2002;20:1445-1450.

36. Joseph J, Saubi N, Pezzat E, and Gatell JM: Progress towards an HIV vaccine based on recombinant Bacillus Calamette-Guerin: Failures and challenges. Expert Rev Vaccines 2006;5:827838.

37. Buonaguro L, Tornesello ML, Tagliamonte M, et al.: Baculovirusderived human immunodeficiency virus type 1 virus-like particles activate dendritic cells and induce ex vivo T-cell responses. rol 2006;80:9134-9143.

38. Lundholm P, Leandersson A-C, Christensson B, Bratt G, Sandstrom E, and Wahren B: DNA mucosal HIV vaccine in humans. Virus Res 2002;82:141-145.

39. Singh M, Vajdy M, Gardner J, Briones M, and O'Hagan D: Mucosal immunization with HIV-1 gag DNA on cationic microparticles prolongs gene expression and enhances local and systemic immunity. Vaccine 2001;20:594-602.

40. Albu DI, Jones-Trower A, Woron AM, Stellrecht K, Broder CC, and Metzger DW: Intranasal vaccination using interleukin-12 and cholera toxin subunit B as adjuvants to enhance mucosal and systemic immunity to human immunodeficiency virus type 1 glycoproteins. J Virol 2003;77:5589-5597.

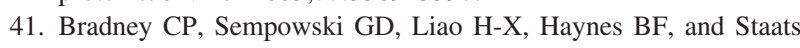
HF: Cytokines as adjuvants for the induction of anti-human immunodeficiency virus peptide immunoglobulin $\mathrm{G}(\mathrm{IgG})$ and $\operatorname{Ig} \mathrm{A}$ antibodies in serum and mucosal secretions after nasal immunization. J Virol 2002;76:517-524.

42. Wu $\mathrm{HY}$ and Russell MW: Induction of mucosal immunity by intranasal application of a streptococcal surface protein antigen with the cholera toxin B subunit. Infect Immun 1993;61:314-322.

43. Donnelly S, Loscher CE, Lynch MA, and Mills KHG: Whole-cell but not acellular pertussis vaccines induce convulsive activity in mice: Evidence of a role for toxin-induced interleukin-1 beta in a new murine model for analysis of neuronal side effects of vaccination. Infect Immun 2001;69:4217-4223.

44. Mutsch M, Zhou W, Rhodes P, et al.: Use of the inactivated intranasal influenza vaccine and the risk of Bell's palsy in Switzerland. N Engl J Med 2004;350:896-903.

45. van Ginkel FW, Jackson RJ, Yuki Y, and McGhee JR: Cutting edge: The mucosal adjuvant cholera toxin redirects vaccine proteins into olfactory tissues. 2000;165:4778-4782.

46. Belyakov IM, Ahlers J, and Berzofsky JA: Mucosal AIDS vaccines: Current status and future. Expert Rev Vaccines 2004;3: S65-73.

47. Eriksson $\mathrm{K}$ and Holmgren J: Recent advances in mucosal vaccines and adjuvants. Curr Opin Immunol 2002;14:666-672.
48. Yuki Y and Kiyono H: New generation of mucosal adjuvants for the induction of protective immunity. Rev Med Virol 2003;13:293-310. US Patent No. 6,015,832, 2000.

49. Hamouda T, Myc A, Donovan B, Shih AY, Reuter JD, and Baker JRJ: A novel surfactant nanoemulsion with a unique non-irritant topical antimicrobial activity against bacteria, enveloped viruses and fungi. Microbiol Res 2001;156:1-7.

50. Myc A, Kukowska-Latallo JF, Bielinska AU, et al.: Development of immune response that protects mice from viral pneumonitis after a single intranasal immunization with influenza A virus and nanoemulsion. Vaccine 2003;21:3801-3814.

51. Bielinska AU, Janczak KW, Landers JJ, et al.: Mucosal immunization with a novel nanoemulsion-based recombinant anthrax protective antigen vaccine protects against Bacillus anthracis spore challenge. Infect Immun 2007;75:4020-4029.

52. Moldoveanu Z, Love-Homan L, Huang WQ, and Krieg AM: CpG DNA, a novel immune enhancer for systemic and mucosal immunization with influenza virus. Vaccine 1998;16:1216-1224.

53. Li M, Gao F, Mascola JR, et al.: Human immunodeficiency virus type 1 env clones from acute and early subtype B infections for standardized assessments of vaccine-elicited neutralizing antibodies. J Virol 2005;79:10108-10125.

54. Montefiori DC: Evaluating neutralizing antibodies against HIV, SIV and SHIV in luciferase reporter gene assays. In: Current Protocols in Immunology (Coligan J, Kruisbeek A, Margulies D, Shevach E, Strober W, and Coico R, eds.). John Wiley \& Sons, New York, 2004, pp. 12.11.11-12.11.15.

55. Mascola JR: Defining the protective antibody response to HIV-1. Curr Mol Med 2003;3:209-216.

56. Kwong PD, Wyatt R, Robinson J, Sweet RW, Sodroski J, and Hendrickson WA: Structure of an HIV gp120 envelope glycoprotein in complex with the CD4 receptor and a neutralizing human antibody. Nature 1998;393:648-659.

57. Holmgren $\mathrm{J}$ and Czerkinsky C: Mucosal immunity and vaccines. Nat Med 2005;11(4 Suppl.):S45-53.

58. O'Hagan DT, Ugozzoli M, Barackman J, et al.: Microparticles in MF59, a potent adjuvant combination for a recombinant protein vaccine against HIV-1. Vaccine 2000;18:1793-1801.

59. Vajdy M and Singh M: Intranasal delivery of vaccines against HIV. Expert Opin Drug Deliv 2006;3:247-259.

60. Varona-Santos JT, Vazquez-Padron RI, and Moreno-Fierros L: Production of a short recombinant C4V3 HIV-1 immunogen that induces strong anti-HIV responses by systemic and mucosal routes without the need of adjuvants. Viral Immunol 2006;19:237-249.

61. Buonaguro L, Racioppi L, Tornesello ML, et al.: Induction of neutralizing antibodies and cytotoxic T lymphocytes in BALB/c mice immunized with virus-like particles presenting a gp120 molecule from a HIV-1 isolate of clade A. Antiviral Res 2002;54:189-201.

62. Mascola JR, Sambor A, Beaudry K, et al.: Neutralizing antibodies elicited by immunization of monkeys with DNA plasmids and recombinant adenoviral vectors expressing human immunodeficiency virus type 1 proteins. J Virol 2005;79:771-779.

63. Wu L, Kong W-p, and Nabel GJ: Enhanced breadth of CD4 T-cell immunity by DNA prime and adenovirus boost immunization to human immunodeficiency virus Env and Gag immunogens. J Virol 2005;79:8024-8031.

64. Holmgren J, Adamsson J, Anjuere F, et al.: Mucosal adjuvants and anti-infection and anti-immunopathology vaccines based on cholera toxin, cholera toxin B subunit and CpG DNA. Immunol Lett 2005;97:181-188.

65. Johansson E-L, Wassen L, Holmgren J, Jertborn M, and Rudin A: Nasal and vaginal vaccinations have differential effects on antibody responses in vaginal and cervical secretions in humans. Infect Immun 2001;69:7481-7486.

66. Kozlowski PA, Cu-Uvin S, Neutra MR, and Flanigan TP: Comparison of the oral, rectal, and vaginal immunization routes for in- 
duction of antibodies in rectal and genital tract secretions of women. Infect Immun 1997;65:1387-1394.

67. Johansson E-L, Rask C, Fredriksson M, Eriksson K, Czerkinsky $\mathrm{C}$, and Holmgren J: Antibodies and antibody-secreting cells in the female genital tract after vaginal or intranasal immunization with cholera toxin B subunit or conjugates. Infect Immun 1998;66: 514-520.

68. Mestecky J: Humoral immune responses to the human immunodeficiency virus type-1 (HIV-1) in the genital tract compared to other mucosal sites. J Reprod Immunol 2006;72:1-17.

69. Russell MW and Mestecky J: Humoral immune responses to microbial infections in the genital tract. Microbes Infect 2002;4: 667-677.

70. Li Y, Svehla K, Mathy NL, Voss G, Mascola JR, and Wyatt R: Characterization of antibody responses elicited by human immunodeficiency virus type 1 primary isolate trimeric and monomeric envelope glycoproteins in selected adjuvants. J Virol 2006;80: 1414-1426.

71. Mascola JR, D'Souza P, Gilbert P, et al.: Recommendations for the design and use of standard virus panels to assess neutralizing antibody responses elicited by candidate human immunodeficiency virus type 1 vaccines. J Virol 2005;79:10103-10107.

72. Goodenow MM and Collman RG: HIV-1 coreceptor preference is distinct from target cell tropism: A dual-parameter nomenclature to define viral phenotypes. J Leukoc Biol 2006;80:965-972.

73. Gorse GJ, Corey L, Patel GB, et al: : HIV $-1 \mathrm{MN}$ recombinant glycoprotein gp160 vaccine-induced cellular and humoral immunity boosted with HIV-1MN recombinant glycoprotein 120 vaccine. National Institute of Allergy and Infectious Diseases AIDS Vaccine Evaluation Group. AIDS Res Hum Retroviruses 1999;15:115-132.

74. Wrin T, Loh TP, Vennari JC, Schuitemaker H, and Nunberg JH: Adaptation to persistent growth in the $\mathrm{H} 9$ cell line renders a primary isolate of human immunodeficiency virus type 1 sensitive to neutralization by vaccine sera. J Virol 1995;69:39-48.

75. Andrianov AM and Veresov VG: Determination of structurally conservative amino acids of the HIV-1 protein gp120 V3 loop as promising targets for drug design by protein engineering approaches. Biochemistry (Moscow) 2006;V71:906-914.
76. Carmichael A, Jin X, and Sissons P: Analysis of the human envspecific cytotoxic T-lymphocyte (CTL) response in natural human immunodeficiency virus type 1 infection: Low prevalence of broadly cross-reactive env-specific CTL. J Virol 1996;70: 8468-8476.

77. Bradley LM, Dalton DK, and Croft M: A direct role for IFN-gamma in regulation of Th1 cell development. J Immunol 1996;157: $1350-1358$.

78. Mosmann TR: T lymphocyte subsets, cytokines, and effector functions. Ann NY Acad Sci 1992;664:89-92.

79. Kornbluth RS and Stone GW: Immunostimulatory combinations: Designing the next generation of vaccine adjuvants. J Leukoc Biol 2006;80:1084-1102.

80. Hartmann G, Weeratna RD, Ballas ZK, et al.: Delineation of a CpG phosphorothioate oligodeoxynucleotide for activating primate immune responses in vitro and in vivo. J Immunol 2000;164: $1617-1624$.

81. Klinman DM, Xie H, and Ivins BE: CpG oligonucleotides improve the protective immune response induced by the licensed anthrax vaccine. Ann NY Acad Sci 2006;1082:137-150.

82. Kojima Y, Xin K-Q, Ooki T, et al.: Adjuvant effect of multi-CpG motifs on an HIV-1 DNA vaccine. Vaccine 2002;20:2857-2865.

83. VanCott TC, Kaminski RW, Mascola JR, et al.: HIV-1 neutralizing antibodies in the genital and respiratory tracts of mice intranasally immunized with oligomeric gp160. J Immunol 1998;160:2000-2012.

84. Greene S, Fortier A, Dijkstra J, et al.: Liposomal vaccines. Adv Exp Med Biol 1995;383:83-92.

Address reprint request to: James R. Baker, Jr. University of Michigan-MNIMBS 1150 West Medical Center Drive 9220 MSRB III

Ann Arbor, Michigan 48109

E-mail: jbakerjr@umich.edu 
This article has been cited by:

1. Angelia Colwell Berkowitz, Diane M. Goddard. 2009. Novel Drug Delivery Systems. Journal of Neuroscience Nursing 41:2, 115-120. [CrossRef] 